\title{
Awareness and Practices of Minimal Invasive Dentistry amongst Dental Interns - A Descriptive Analysis
}

\author{
Raksha Bhat ${ }^{1}$, Preethesh Shetty ${ }^{2}$, Farhan Ariwala ${ }^{3}$, Arjun Hegde ${ }^{4}$, Arjun $\mathrm{Kini}^{5}$
}

\begin{abstract}
${ }^{1}$ Department of Conservative Dentistry and Endodontics, A. B. Shetty Memorial Institute of Dental Sciences, Nitte (Deemed to be University), Mangaluru, Karnataka, India. ${ }^{2}$ Department of Conservative Dentistry and Endodontics, A. B. Shetty Memorial Institute of Dental Sciences, Nitte (Deemed to be University), Mangaluru, Karnataka, India. ${ }^{3}$ Department of Conservative Dentistry and Endodontics, A. B. Shetty Memorial Institute of Dental Sciences, Nitte (Deemed to be University), Mangaluru, Karnataka, India. ${ }^{4}$ Department of Conservative Dentistry, Faculty of Dentistry, Melaka Manipal Medical College,

Manipal Academy of Higher Education, Manipal, Karnataka, India. ${ }^{5}$ Department of Conservative Dentistry and Endodontics, A. B. Shetty Memorial Institute of Dental Sciences, Nitte (Deemed to be University), Mangaluru, Karnataka, India.
\end{abstract}

\section{ABSTRACT}

\section{BACKGROUND}

The current approach to management of caries has evolved towards minimal invasive dentistry comprising of early diagnosis of incipient lesions, remineralization and conservative dental treatment with minimal intervention if required. Despite the focus of the dental curriculum on minimal invasive dentistry, not much of it is adopted into practice by the students. We wanted to assess the knowledge, attitude, and skills of minimal invasive dentistry amongst the dental interns of Dakshina Kannada district.

\section{METHODS}

The data was gathered through an online questionnaire developed and validated by experts.

\section{RESULTS}

A total of 244 dental interns responded to the online questionnaire survey. Majority was aware of the principles of minimal invasive dentistry mainly through lectures, although not many had practiced it. Fluoride treatment was the most recommended treatment for the prevention of caries. Although most of them agreed that caries risk assessment was effective, nearly half of them had never practiced it. A greater part of the respondents agreed upon the effectiveness of preventive measures and conservative modalities of treatment in the current day practice.

\section{CONCLUSIONS}

Despite the awareness and knowledge of minimal invasive dentistry amongst the interns of Dakshina Kannada population, the practice of minimal invasive dentistry should be taught to the students and should be implemented in routine dental practice.

\section{KEY WORDS}

Minimal Invasive Technique, Descriptive Study, Awareness, Dental Interns, Questionnaire Study
Corresponding Author:

Dr. Preethesh Shetty,

Department of Conservative Dentistry and Endodontics, $3^{\text {rd }}$ Floor,

A. B. Shetty Memorial Institute of Dental Sciences, Nitte (Deemed to be University), Deralakatte,

Mangaluru-575018, Karnataka, India.

E-mail:drpreetheshshetty@nitte.edu.in

DOI: $10.14260 /$ jemds/2020/492

How to Cite This Article:

Bhat $R$, Shetty $P$, Ariwala F, et al. Awareness and practices of minimal invasive dentistry amongst dental interns- a descriptive analysis. J. Evolution Med. Dent. Sci. 2020;9(32):2270-2273, 10.14260/jemds/2020/492

Submission 04-05-2020,

Peer Review 30-06-2020,

Acceptance 06-07-2020,

Published 10-08-2020.

Copyright (C) 2020 JEMDS. This is an open access article distributed under Creative Commons Attribution License [Attribution 4.0 International (CC BY 4.0)] 


\section{BACKGROUND}

"Extension for prevention" advocated by G.V. Black remains the traditional restorative approach in dental practice. This invasive approach to control caries progression leads to repeat restorative cycle, due to which the cavity preparation gets larger, and the tooth structure gets weaker with each time the restoration is repeated.[1] However, with time there has been progression in research leading to changing concepts of cariology in terms of pathogenesis of dental caries, transmission, the demineralisation-remineralisation cycle and with the advent of newer technologies in biomaterials, equipment's used for the detection of carious lesions and various methods for cavity preparation. This scientific basis of knowledge when combined with the technological and technique related developments, imply that the legit therapeutic model is the one based on prevention and treatment of dental caries, using the least invasive of all approaches. This model of care with a rational approach is known as minimal intervention dentistry. ${ }^{[2]}$

Minimally Invasive Dentistry is a conservative dental restorative philosophy that emphasizes on assessment of caries risk, early detection of carious lesions, remineralisation of demineralized tooth structure and, most importantly the preservation of tooth structure through minimal intervention during the placement and replacement of restorations. Management of carious lesions by minimal intervention, includes the following principles: Identification of the carious lesion risk assessment and at the earliest stage of demineralization, remineralisation therapy for primary prevention against the formation of new carious lesions, conservative caries removal to control an established lesion, using adhesive restorative materials for small but smart restorations and repair of the restorations rather than replacement.[3-5]

The dental college training, practice, and experience determine the ability of a dental surgeon to adopt novel methods as a minimal intervention.[6] However, in recent times fundamental aspects of care to arrest initial caries progression and prevent the formation of the cavity as the prime measure to control caries is stressed upon in academia and these approaches have been incorporated in the structure of various dental curricula worldwide.[7-10] Despite these raging trends toward conservative treatment, there exists an ambiguity about the awareness of this rational approach amongst the dental interns and whether the knowledge acquired on minimal invasive dentistry during their academic period transcribes into clinical practice. The present study evaluates the knowledge, attitude, practices and clinical decision behaviours of dental interns in Mangaluru city, India to decipher if the knowledge attained during the academic course helps students develop a positive attitude towards practicing minimally invasive dentistry.

\section{METHODS}

This was a cross sectional study. The survey period was from September to December 2018. Sample size was determined by using Survey Sample Size Calculator $(95 \%$ confidence interval). Sample size calculated was 244 from amongst 600 dental interns in various colleges in Mangaluru, Karnataka. Informed written consent was obtained from 244 dental interns who volunteered for the study. The objectives and rationale were given in an information letter attached to the link to the questionnaire.

\section{Questionnaire}

The questionnaire was circulated to all dental interns using the link for Google Forms, sent to all the interns through E-mail as well as through printed forms. Questions were formulated based on diagnosis and detection of caries, remineralisation therapy for initial carious lesions and minimal invasive dentistry application in clinical practice. The questions were directed towards aetiology, prevention, and application of minimal invasive principles for control of carious process, various techniques used for the detection of caries, counselling for dietary changes, application of pit and fissure sealants, and ultra-conservative restorative procedures.

The questionnaire was divided into two sections. The first section assessed the gender and age of the dental interns. The second section assessed the knowledge and approach related to minimal invasive dentistry in clinical practice.

The questionnaire was validated by establishing face validity, i.e. by two experts in the field were asked to read through and validate the questionnaire. Cronbach's alpha factor was determined prior to initiation of the study to ascertain the reliability and consistency of the questionnaire valued at 0.7 .

The questionnaire was circulated to all dental interns using the link for Google Forms, sent to all the interns through.

\section{Statistical Analysis}

Descriptive analysis with frequency and percentage was performed as there was no need to establish statistical inter comparisons.

\section{RESULTS}

A total of 244 completely filled questionnaires were analysed, which included both online as well as written responses. The age of the applicants ranged from 22 to 26 years (mean $23.18 \pm 1.39$ years). Of the 244 dental interns, 118 (48.3\%) were males, and $126(51.6 \%)$ were females.

A vast majority (92\%) of dental interns were acquainted to the concepts of Minimal Invasive Dentistry through the curriculum. The knowledge and approach of the interns towards Minimal Invasive Dentistry were determined separately.

Most of the applicants agreed that fluoride was an effective method of preventing dental caries $(147,60.2 \%)$. There was a relatively high number of applicants who were uncertain $(60$, $24.5 \%)$ or agreed $(48,19.6 \%)$ regarding the fact that G.V. Black's extension for prevention is relevant for initial caries.

Most of the respondents were aware that hand instruments $(236,96.7 \%)$ are used in atraumatic restorative treatment, with unfilled resin used as a pit and fissure sealant (188, 77\%). They were also aware of the importance of fluoride as a caries preventive measure $(172,70.4 \%)$. 
Most (92\%) of dental interns were acquainted to the concepts of Minimal Invasive Dentistry through the curriculum. This can help to explain why certain questions which pertained to the practice of MID, yielded a negative response. For example, $117(47.9 \%)$ of the applicants did not perform preventive resin restorations, while 97(39.7\%) did not practice Atraumatic Restorative Treatments (ART).

It was also seen that most of the preventive measures which are a part of MID, was either unknown to the participants, or not practiced. It was seen that caries risk assessment $(108,44.2 \%)$ as well as application of fluoride varnishes $(118,45.9 \%)$ were performed only sometimes by the majority of the participants of the study.

Regarding the prescription of more conservative treatment modalities for caries prevention, 112 (45.9\%) of the participants rarely prescribed chlorhexidine mouthwashes. It was also seen that although most of the participants did recognize the importance of sugar with caries formation, only $72(29.4 \%)$ of the applicants believed in recommending xylitol chewing gums to their patients.

\begin{tabular}{|c|c|c|c|c|c|}
\hline 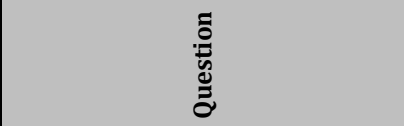 & 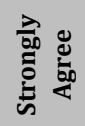 & 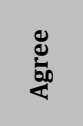 & 胥 & 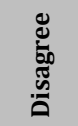 & 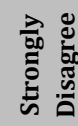 \\
\hline $\begin{array}{c}\text { Do you think fluoride is an effective way } \\
\text { of preventing dental caries }\end{array}$ & $\begin{array}{c}64 \\
26.2 \%\end{array}$ & $\begin{array}{c}147 \\
60.2 \%\end{array}$ & $\begin{array}{c}25 \\
10.2 \%\end{array}$ & $\begin{array}{c}8 \\
3.2 \%\end{array}$ & 0 \\
\hline $\begin{array}{l}\text { Do you think G.V Black's 'extension for } \\
\text { prevention' is relevant for initial caries }\end{array}$ & $\begin{array}{c}8 \\
3.2 \%\end{array}$ & $\begin{array}{c}40 \\
16.3 \%\end{array}$ & $\begin{array}{c}60 \\
24.5 \%\end{array}$ & $\begin{array}{c}73 \\
29.9 \%\end{array}$ & $\begin{array}{c}63 \\
25.8 \%\end{array}$ \\
\hline $\begin{array}{c}\text { Do you think adhesive restorative } \\
\text { materials have helped in preserving tooth } \\
\text { structure }\end{array}$ & $\begin{array}{c}85 \\
34.8 \%\end{array}$ & $\begin{array}{c}146 \\
59.8 \%\end{array}$ & $\begin{array}{c}11 \\
4.5 \%\end{array}$ & 0 & $\begin{array}{c}2 \\
0.8 \%\end{array}$ \\
\hline $\begin{array}{l}\text { Do you think caries risk assessment } \\
\text { should be carried out for all patients }\end{array}$ & $\begin{array}{c}52 \\
21.3 \%\end{array}$ & $\begin{array}{c}156 \\
63.9 \%\end{array}$ & $\begin{array}{c}29 \\
11.8 \%\end{array}$ & $\begin{array}{c}7 \\
2.8 \%\end{array}$ & 0 \\
\hline $\begin{array}{l}\text { Do you think applying pit and fissure } \\
\text { sealants is beneficial? }\end{array}$ & $\begin{array}{c}53 \\
21.7 \%\end{array}$ & $\begin{array}{c}131 \\
53.6 \%\end{array}$ & $\begin{array}{c}52 \\
21.3 \%\end{array}$ & $\begin{array}{c}8 \\
3.2 \%\end{array}$ & 0 \\
\hline $\begin{array}{r}\text { Table 1. Analysis of the Aware } \\
\text { Invasive Dentistry a }\end{array}$ & $\begin{array}{l}\text { eness } \\
\text { mong }\end{array}$ & $\begin{array}{l}\text { he Cor } \\
\text { Dental }\end{array}$ & $\begin{array}{l}\text { cepts o } \\
\text { nterns }\end{array}$ & f Minir & \\
\hline
\end{tabular}

\begin{tabular}{|c|c|c|c|c|c|}
\hline Question & Never & Rarely & Sometimes & Often & $\begin{array}{l}\text { Most of } \\
\text { the time }\end{array}$ \\
\hline $\begin{array}{l}\text { Do you carry out a caries } \\
\text { risk assessment? }\end{array}$ & $\begin{array}{c}16 \\
6.5 \%\end{array}$ & $\begin{array}{c}52 \\
21.3 \%\end{array}$ & $\begin{array}{c}108 \\
44.2 \%\end{array}$ & $\begin{array}{c}52 \\
21.3 \%\end{array}$ & $\begin{array}{c}16 \\
6.5 \%\end{array}$ \\
\hline $\begin{array}{l}\text { Do you perform } \\
\text { remineralisation with } \\
\text { topical fluoride? }\end{array}$ & $\begin{array}{c}13 \\
5.3 \%\end{array}$ & $\begin{array}{c}7 \\
2.8 \%\end{array}$ & $\begin{array}{c}102 \\
41.8 \%\end{array}$ & $\begin{array}{c}83 \\
34 \%\end{array}$ & $\begin{array}{c}39 \\
15.9 \%\end{array}$ \\
\hline $\begin{array}{l}\text { Do you think the use of } \\
\text { fluoride varnishes is NOT a } \\
\text { cost-effective method? }\end{array}$ & $\begin{array}{c}72 \\
29.5 \%\end{array}$ & $\begin{array}{c}72 \\
29.5 \%\end{array}$ & $\begin{array}{c}67 \\
27.4 \%\end{array}$ & $\begin{array}{c}33 \\
13.5 \%\end{array}$ & 0 \\
\hline $\begin{array}{l}\text { Do you seal adjacent pits and } \\
\text { fissures of composite } \\
\text { restorations with a sealant? }\end{array}$ & $\begin{array}{c}46 \\
18.8 \%\end{array}$ & $\begin{array}{c}67 \\
27.4 \%\end{array}$ & $\begin{array}{c}60 \\
24.5 \%\end{array}$ & $\begin{array}{c}63 \\
25.8 \%\end{array}$ & $\begin{array}{c}8 \\
3.2 \%\end{array}$ \\
\hline $\begin{array}{l}\text { Do you repair defective } \\
\text { restorations instead of } \\
\text { replacement? }\end{array}$ & $\begin{array}{c}69 \\
28.2 \%\end{array}$ & $\begin{array}{c}35 \\
14.3 \%\end{array}$ & $\begin{array}{c}103 \\
42.2 \%\end{array}$ & $\begin{array}{c}23 \\
9.4 \%\end{array}$ & $\begin{array}{c}14 \\
5.7 \%\end{array}$ \\
\hline $\begin{array}{l}\text { Do you practice atraumatic } \\
\text { restorative treatment? }\end{array}$ & $\begin{array}{c}20 \\
8.1 \%\end{array}$ & $\begin{array}{c}83 \\
34 \%\end{array}$ & $\begin{array}{c}97 \\
39.7 \%\end{array}$ & $\begin{array}{c}32 \\
13.1 \%\end{array}$ & $\begin{array}{c}13 \\
5.3 \%\end{array}$ \\
\hline
\end{tabular}

\section{DISCUSSION}

Current concepts of minimally invasive dentistry for prevention and treatment of primary caries lesions mainly include limited tooth preparations confined to removal of caries.[11] Adaptation of these preventive concepts have led to the decline of caries in the recent years. Although, the decisions of adopting the preventive or minimal invasive methodology can be determined only by the knowledge and attitude of the clinician towards these practices.

Contemporary views suggest dental caries is not an infectious disease, hence complete removal of carious tissue is not an absolute necessity.[12] Once all the preventive measures such as biofilm control, remineralisation strategies and sealing fails, operative treatment is recommended.[13,14] Cavitated lesions with proximal lesions extending beyond the outer third of the dentine, confirmed on bitewing radiographs even if unable to be identified clinically are considered for operative intervention.[15]

However, through the answers obtained in the present study, it was observed that the traditional treatment with invasive interventions continues to be the treatment modality in all kinds of carious lesions, undeterred by the research and novel advancements in the field of material science as well as cariology. The answers received towards operative treatment from the interns were more precise compared to the answers towards preventive treatment. Hence, evidence based professional development programs need to be conducted for undergraduate students in addition to the the minimal invasive concepts taught in the curriculum for enhanced knowledge and training in the field.[16]

Achieving a favourable outline in MID for the management of dental caries relies on the Caries Risk Assessment as its foundation.[17] In the present study, 44.9\% of interns agreed that it should be done for all the patients. There was an acceptable response to non-fluoridated preventive treatment such as chewing gum and mints infused with Xylitol or remineralizing agents such as CPP-ACP, amorphous calcium phosphate, calcium sodium phosphosilicate and beta tricalcium phosphate. Despite a majority of the interns agreeing to fluoride being the fundamental factor in the process of remineralisation of the tooth structure, only a few recommend preventive fluoride treatment in clinical practice. Fluorides has proven to be proficient in the remineralisation process.[18] Hence, knowledge and training of caries risk assessment and preventive treatment should be emphasized onto the students in addition to the curriculum.

Although most of the interns acknowledged the effectiveness of Atraumatic Restorative treatment and pit and fissure sealants, only a few claimed to imbibe that into their clinical practice. The knowledge about ART however could be attributed to the comprehensive use of glass ionomer cements. Also, it has to be understood that sealants are fundaments towards the approach of Minimal Invasive Dentistry and are indicated to also seal the open margins of old restorations in addition to the noncavitated occlusal caries lesions and deep pits and fissures.

The major limitations of the present study is that it involves only the interns of the colleges in the Dakshina Kannada District of Karnataka, which is relatively a small sample to device their perceptions and practice of the principles of Minimal Invasive Dentistry. Additional supplementary surveys have to be done in a geographically wider area with an increased sample size involving students from various parts of the nation and round the globe. 


\section{CONCLUSIONS}

Due to the inclusion of the principles of minimal invasive dentistry into the curriculum, the interns have satisfactory knowledge of the subject but do not follow the same in clinical practice. There is a need for educating and implementing the practices of MID as routine procedures in clinical practice during undergraduate training along with the regular professional development programs.

Financial or Other Competing Interests: None.

\section{REFERENCES}

[1] Elderton RJ. Preventive (evidence-based) approach to quality general dental care. Med Princ Pract 2003;12 Suppl 1:12-21.

[2] Sheiham A. Minimal intervention in dental care. Med Princ Pract 2002;11(Suppl 1):2-6.

[3] Holmgren C, Gaucher C, Decerle N, et al. Minimal intervention dentistry II: Part 3. Management of noncavitated (initial) occlusal caries lesions - non-invasive approaches through remineralisation and therapeutic sealants. Br Dent J 2014;216(5):237-43.

[4] Fédération Dentaire Internationale (FDI) General Assembly: September 2016, Poznan, Poland; Policy Statement (revision) Minimal Intervention Dentistry (MID) 2016:4-5.

[5] Walsh LJ, Brostek AM. Minimum intervention dentistry principles and objectives. Aust Dent J 2013;58 Suppl 1:316.

[6] Frencken JE, Peters MC, Manton DJ, et al. Minimal intervention dentistry for managing dental caries - a review: report of a FDI task group. Int Dent J 2012;62(5):223-43.

[7] Guerrieri A, Gaucher C, Bonte E, et al. Minimal intervention dentistry: Part 4. Detection and diagnosis of initial caries lesions. Br Dent J 2012;213(11):551-7.

[8] Ngo H, Opsahl-Vital S. Minimal intervention dentistry II: Part 7. Minimal intervention in cariology: the role of glassionomer cements in the preservation of tooth structures against caries. Br Dent J 2014;216(10):561-5.

[9] Tseveenjav B, Vehkalahti M, Murtomaa H. Time and cohort changes in preventive practice among Mongolian dental students. Eur J Dent Educ 2003;7(4):177-81.

[10] Pakdaman A, Evans RW, Howe E. Dental students' knowledge and perceptions of non-invasive dental caries management. Aust Dent J 2010;55(1):28-36.

[11] Laske M, Opdam NJM, Bronkhorst EM, et al. Minimally invasive intervention for primary caries lesions: are dentists implementing this concept? Caries Res 2019;53(2):204-16.

[12] Ricketts D, Lamont T, Innes NP, et al. Operative caries management in adults and children. Cochrane Database Syst Rev 2013;(3):CD003808.

[13] Marinho VCC, Worthington HV, Walsh T, et al. Fluoride varnishes for preventing dental caries in children and adolescents. Cochrane Database Syst Rev 2013;(7):CD002279.

[14] Dorri M, Dunne SM, Walsh T, et al. Micro-invasive interventions for managing proximal dental decay in primary and permanent teeth. Cochrane Database Syst Rev 2015;(11):CD010431.

[15] Meyer-Lueckel H, Paris S. When and how to intervene in the caries process. Oper Dent 2016;41(S7):S35-47.

[16] Rayapudi J, Usha C. Knowledge, attitude and skills of dental practitioners of Puducherry on minimally invasive dentistry concepts: a questionnaire survery. J Conserv Dent 2018;21(3):257-62.

[17] Philip N. State of the art enamel remineralization systems: the next frontier in caries management. Caries Res 2019;53(3):284-95.

[18] Hallett KB. The application of caries risk assessment in minimum intervention dentistry. Aust Dent J 2013;58 Suppl 1:26-34. 